\title{
DETERMINISTIC MODEL OF HEADWAY DISTURBANCE PROPAGATION ALONG AN URBAN PUBLIC TRANSPORT LINE
}

\author{
Pavle Pitka, Milan Simeunović, Ilija Tanackov, Tatjana Savković
}

Original scientific paper

In an urban public transport system, the primary disturbance in the headway arising in the context of departure times has a tendency to propagate through the system. In this paper, by analyzing the movement of vehicles along a specific transport line, the parameters affecting the propagation of the headway disturbance were identified. The established links between these parameters were utilized in the development of a deterministic model. The model describes the propagation of disturbance in the headway by stops along the line, as well as scheduled vehicles at one urban public transport line. The analysis revealed that the number of stops along the line and the passenger boarding intensity have the most significant effect on the propagation of disturbance in the headway.

Keywords: deterministic model; dwell time; headway; urban public transport

Deterministički model širenja poremećaja intervala slijeđenja vozila na linijama javnog gradskog prijevoza putnika

Izvorni znanstveni članak U sustavu javnog gradskog prijevoza, primarni poremećaj intervala slijeđenja vozila koji nastaje unutar jednog polaska, ima tendenciju širenja u sustavu. U ovom radu analizom procesa kretanja vozila duž linije, identificirani su parametri koji utiču na širenje poremećaja intervala slijeđenja. Na osnovu utvrđenih relacija između parametara formiran je deterministički model. Modelom je predstavljeno širenje poremećaja intervala slijeđenja po stajalištima duž linije i po polascima u voznom redu na jednoj liniji javnog gradskog prijevoza. Analizom je utvrđeno da najznačajniji uticaj na širenje poremećaja intervala slijeđenja vozila u sustavu imaju: broj stajališta i odnos intenziteta nakupljanja putnika i intenziteta ulaska putnika u vozilo.

Ključne riječi: deterministički model; interval slijeđenja vozila; javni gradski prijevoz; zadržavanje vozila na stajalištu

\section{Introduction}

Service quality and system stability of public passenger transport (PPT), among other factors, depends on the degree of headway uniformity. In systems lacking strategies for managing headway disparities, due to a large number of factors, disturbances in the vehicle travel patterns emerge. Headway inconsistency reduces the quality of service offered to the user, in terms of increased average passenger waiting time [1] and passenger comfort in the vehicle [2]. Inadequate service quality may thus prompt users to change travel mode, resulting in the decline of public transport utilization.

While the primary disturbance in public transport schedule arises due to diverse factors, it has tendency to propagate across the entire line, affecting subsequent departure times in the daily schedule. In its extreme, headway disturbance propagation results in the vehicle clustering phenomenon [3].

Extant literature reveals divergent perspectives on parameters affecting headway disturbance propagation. This work presents analysis of vehicle travel patterns along one public transport line, as well as identifies parameters leading to the propagation of headway disturbance, which are subsequently ranked according to their contribution to the cumulative increase in disturbance propagation.

The aim of this investigation was not to identify the causes of disturbances in the public transport schedule patterns, as it focused solely on analyzing contributions of specific effects that cause their propagation.

Finally, the determined links between the aforementioned parameters were utilized in the development of a deterministic model describing propagation of headway disturbances by stops along the line, as well as scheduled vehicles at one urban public transport line. In sum, this work, while acknowledging all model limitations, considers complex effects of different parameters on schedule disturbance propagation.

\section{Literature review}

Headway variability, as a vehicle clustering phenomenon, has been studied via mathematical $[4 \div 9]$ and empirical $[10 \div 12]$ models, mostly aiming to develop public transport schedule management strategies. The most common strategies rely on retaining vehicles at specific predetermined stops $[4 \div 8,13]$ and limiting passenger admission along the line [13]. Only a few authors have previously analyzed the effect of individual parameters on the headway variability.

Firstly discovered and highlighted by Newell and Potts [14], the bunching phenomenon appears because the time passengers take to board the bus at a station increases with the time between two consecutive bus arrivals. Vuchic [15] carried out an analogous research in rail systems, using a deterministic model to investigate the propagation of schedule disturbances on specific station along a transit line.

In their study, Xumei et al. [11] conducted empirical analysis of bus service reliability in Beijing, China. The authors examined the effect of line length, headway size, and utilization of lane dedicated for transport use. Service reliability level was assessed via three parameters: punctuality index based on lines, deviation index based on stops, and evenness index based on stops. The analysis results revealed that line length affects all aforementioned parameters; interval size does not affect the bus arrival accuracy; and utilization of designated lane has positive influence of service reliability.

Propagation of headway disturbance affects the travel time. On the other hand, standard deviation of the travel 
time is affected by line length $[12,17]$. Using a stochastic model, Daganzo [16] demonstrated that standard deviation of the travel time increases with the square root of the number of stops. The author proposed introduction of control points along the line, along with slack time, as a solution to this issue.

In his work, Vuchic [15] analyzed propagation of train timetable breaches on public transport lines by examining several consecutive stops. The author concluded that delays are significantly affected by parameter $\beta$, denoting ratio of train dwell time at the station and the time interval between its departure and the arrival of the next scheduled train.

The aforementioned studies have, among other contributions, identified parameters affecting headway. However, most extant research in this field neither analyzed the disturbance propagation effect on the subsequent vehicle nor ranked these parameters based on their influence on the headway disturbance propagation along the line.

\section{Identification of influential parameters}

In this section, parameters affecting the cumulative changes in the headway disturbance are identified, along with the process by which these disturbances are propagated across successive scheduled departures. All parameters pertinent to model development are examined through temporal components of vehicle travel pattern along the line in the travel time, namely: dwell time, running time, and terminal time.

The most relevant processes for model development take place during vehicle dwell time at the stop, i.e., door opening, passenger boarding and alighting, and door closing. Thus, the time the vehicle remains at a scheduled stop can be described by Eq. (1).

$t_{\mathrm{s}}=t_{\mathrm{od}}+t_{\mathrm{ex}}+t_{\mathrm{cd}}$

where: $t_{\mathrm{s}}$ - dwell time at the stop (min); $t_{\mathrm{od}}$ - time required to open the doors $(\mathrm{min}) ; t_{\mathrm{ex}}$ - time required for passenger exchange $(\mathrm{min}) ; t_{\mathrm{cd}}$ - time required to close the doors (min).

Time spent on opening $\left(t_{\mathrm{od}}\right)$ and closing doors $\left(t_{\mathrm{cd}}\right)$ is determined by technical and mechanical vehicle properties and can thus be assumed constant. Moreover, compared to the time required for passengers to board and alight from the vehicle, these components are negligible, i.e., $t_{\mathrm{od}}+t_{\mathrm{cd}}<<<t_{\mathrm{s}}$. In addition, as $t_{\mathrm{od}}$ and $t_{\mathrm{cd}}$ do not affect variability in $t_{s}$, both are omitted from the model.

Passenger exchange incorporates both disembarkation of passengers from the vehicle and intake of new passengers at the scheduled stops along the line. If travel fare is charged or checked at the entry point, the passenger boarding rate is much lower than that of alighting. Thus, passenger exchange time is primarily driven by the time required for passengers to enter the vehicle [4, 9, 19]. In other words, passenger exchange time is determined by the number of individuals entering the vehicle and their average boarding intensity.
$t_{\mathrm{ex}}=\frac{U}{\mu}$,

where: $t_{\mathrm{ex}}$ - passenger exchange time (min); $U$ - number of passengers entering the vehicle; $\mu$ - average boarding intensity (passenger/min).

When headways are shorter than 15 minutes, passenger accumulation at stops is uniform in time and does not depend on transport schedule $[18,19]$. In this case, the number of passengers entering the vehicle depends exclusively on the passenger accumulation intensity and headway.

$U=\lambda \cdot H$

where: $H$ - headway (min); $\lambda$ - passenger accumulation intensity (passenger/min).

It can be concluded that the dwell time is a function of headway, passenger accumulation intensity and average boarding intensity.

$t_{\mathrm{s}}=t_{\mathrm{ex}}=\frac{\lambda \cdot H}{\mu}$

The degree of interaction between public transport subsystems and other modes of surface transport influences the vehicle running time between consecutive stops. In public transport systems that utilize completely independent line (row A), variability in running time between stops are negligible [19]. On the other hand, when vehicles are utilizing fully and partially dependent lines (row B and C), mixed transport flows affect public transport performance. However, while other forms of surface transport create disturbances in the headway, they do not affect their accumulation.

At the terminal, the vehicle is empty and can remain there to accommodate schedule needs. Thus, time spent at the terminal does not contribute to the headway disturbance. This suggests that correct terminal time determination can compensate for headway variability. Model developed in this work disregards terminal time, as it does not affect headway disturbance propagation.

\section{Headway disturbance propagation model}

The deterministic model was developed based on the following assumptions:

- Vehicle running time between adjacent stops is uniform,

- Time required to open and close doors is constant and negligible relative to the dwell time,

- Passenger exchange, i.e., boarding and alighting, occurs simultaneously,

- Number of passengers entering the vehicles is not limited,

- Headway does not exceed 15 minutes,

- Variability in passenger accumulation at stops along the line is constant,

- Vehicles driving along the same line do not overtake one another. 
In the model, headway disturbance propagation is represented by stops along the line and by vehicle schedule position.

In the model, the point at which headway disturbance occurs (stop/departure) is observed relative to a reference point. Reference point is defined as the stop at which the vehicle that caused the primary headway was located.

\subsection{Disturbance propagation by stops along the line}

In ideal conditions, public transport system operates with uniform headway. In other words, each vehicle follows its predecessor uniformly along the line, adhering to the projected headway. When, due to various factors, a delay $h_{\mathrm{p}}$ (primary headway disturbance) in Vehicle 1 arrival at stop $j$ occurs, the dwell time at $j$ also increases (Fig. 1). Extended dwell time is a result of longer passenger exchange time relative to the projected duration, due to the greater number of passengers that have arrived at the stop during the interval $h_{\mathrm{p}}$. Arriving at the subsequent stop $j+1$, Vehicle 1 is delayed not only by $h_{p}$, but also by an additional period dependent on the passenger accumulation intensity as well as passenger boarding intensity. In this manner, delay in the predetermined schedule propagates along the line.

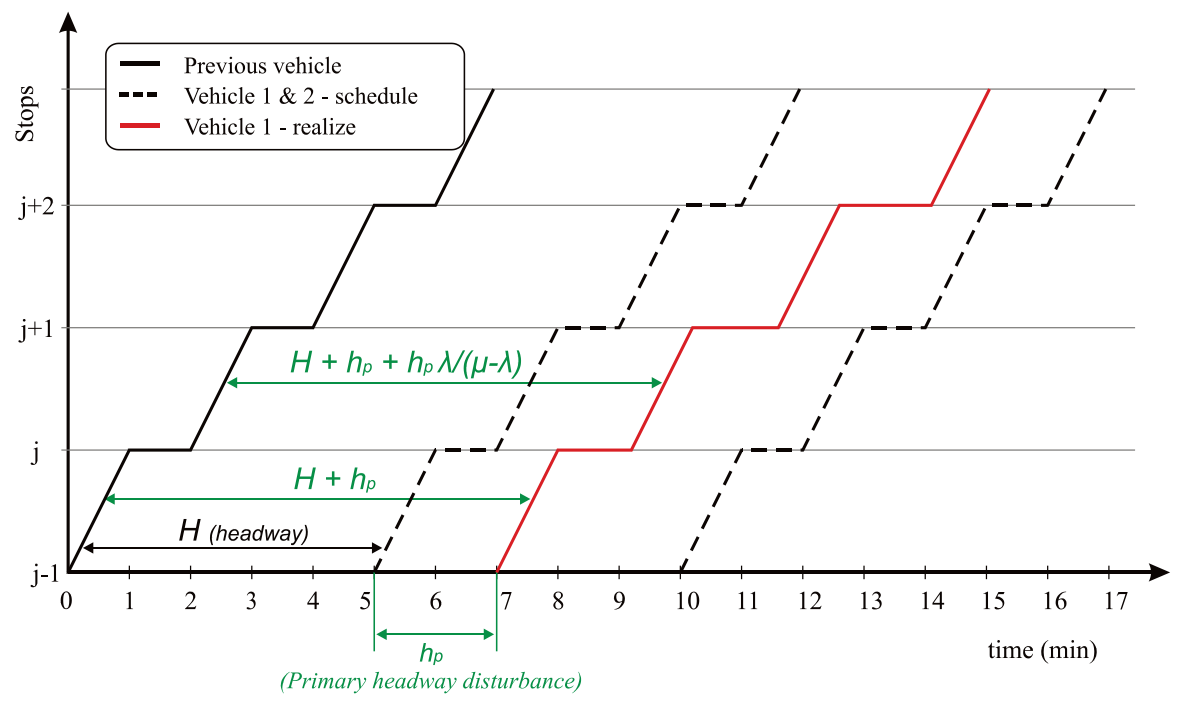

Figure 1 Spatial-temporal diagram of Vehicle 1 headway disturbance propagation

Primary headway disturbance occurred at Stop 1 and represents the difference between the realized and projected headway. Based on the aforementioned assumptions, it can be mathematically expressed by Eq. (5).

$$
h_{\mathrm{p}}=h_{1}=H_{\mathrm{r}}-H \text {, }
$$

where: $h_{\mathrm{p}}$ - primary headway disturbance (min); $h_{1}$ - headway disturbance noted at the first stop (min); $H$ - projected headway $(\mathrm{min}) ; H_{\mathrm{r}}$ - realized headway ( $\mathrm{min})$.

This headway disturbance propagates to the next stop according to Eq. (6).

$h_{2}=h_{1}+h_{1}\left(\frac{\lambda}{\mu}\right)$,

where: $h_{2}$ - headway disturbance noted at the second stop (min); $\lambda$ - mean passenger accumulation intensity along the line (passenger/min); $\mu$ - mean passenger boarding intensity (passenger/min).

By the process of induction, the same relationship can be established between the second and the third stop, i.e., via Eq. (7).

$$
h_{3}=h_{2}+h_{2}\left(\frac{\lambda}{\mu}\right)
$$

Thus, the headway disturbance at the stop $s$ can be described by Eq. (8).

$$
h_{s}=h_{s-1}+h_{s-1}\left(\frac{\lambda}{\mu}\right) \text {, }
$$

where: $h_{s}$ - headway disturbance at the stop $s$ (min); $s$ - number of stops from the one at which the primary headway disturbance occurred.

When the size and location of the primary headway disturbance, mean passenger accumulation intensity at each stop, and passenger boarding intensity are known, it is possible to define a priori headway disturbance propagation along consecutive stops using Eq. (9).

$$
h_{s}=h_{\mathrm{p}}\left(1+\frac{\lambda}{\mu}\right)^{s-1}
$$

\subsection{Headway disturbance propagation by scheduled departures and by stops along the line}

The generated headway disturbance is transmitted to subsequent scheduled departures. The subsequent vehicle 
is affected by the headway inconsistency due to the realized passenger accumulation intensity and time required for boarding of those passengers, at each stop along the line.

Vehicle 2 follows the predetermined schedule (Fig. 2); however, as Vehicle 1 arrived at stop $j$ with the delay $h_{\mathrm{p}}$, the headway for Vehicle 2 is reduced by $h_{\mathrm{p}}$ and becomes $H-h_{\mathrm{p}}$. Vehicle 2 headway reduction at stop $j$ implies fewer accumulated passengers and shorter dwell time at $j$. At the stop $j+1$, Vehicle 2 headway has been further reduced and exhibits a decremental trend.

Vehicle 2 headway reduction is affected by two processes, namely cumulative increase in the Vehicle 1 delay along the line, and cumulative increase in the travel velocity by Vehicle 2 (Fig. 2).

By the same analogy, headway disturbance is transmitted to the schedules of all subsequent vehicles along the line (Vehicle 3, Vehicle 4, etc.). The terminal case for the aforementioned headway inconsistency is represented by vehicle clustering along the line.

General expression describing the headway disturbance propagation by consecutive stops for Vehicle 2 is given by Eq. (10).

$h_{2, s}=h_{2, s-1}+h_{2, s-1}\left(\frac{\lambda}{\mu}\right)-h_{1, s-1}\left(\frac{\lambda}{\mu}\right)$,

where: $h_{k, s}$ - headway disturbance for vehicle $k$ at the stop $s$ (min); $s$-number of stops along the line from the one at which the primary headway disturbance occurred; $k$ - vehicle schedule number relative to the one that has caused the primary headway disturbance; $\lambda$ - mean passenger accumulation intensity (passenger $/ \mathrm{min}$ ); $\mu$ - mean passenger boarding intensity (passenger/min).

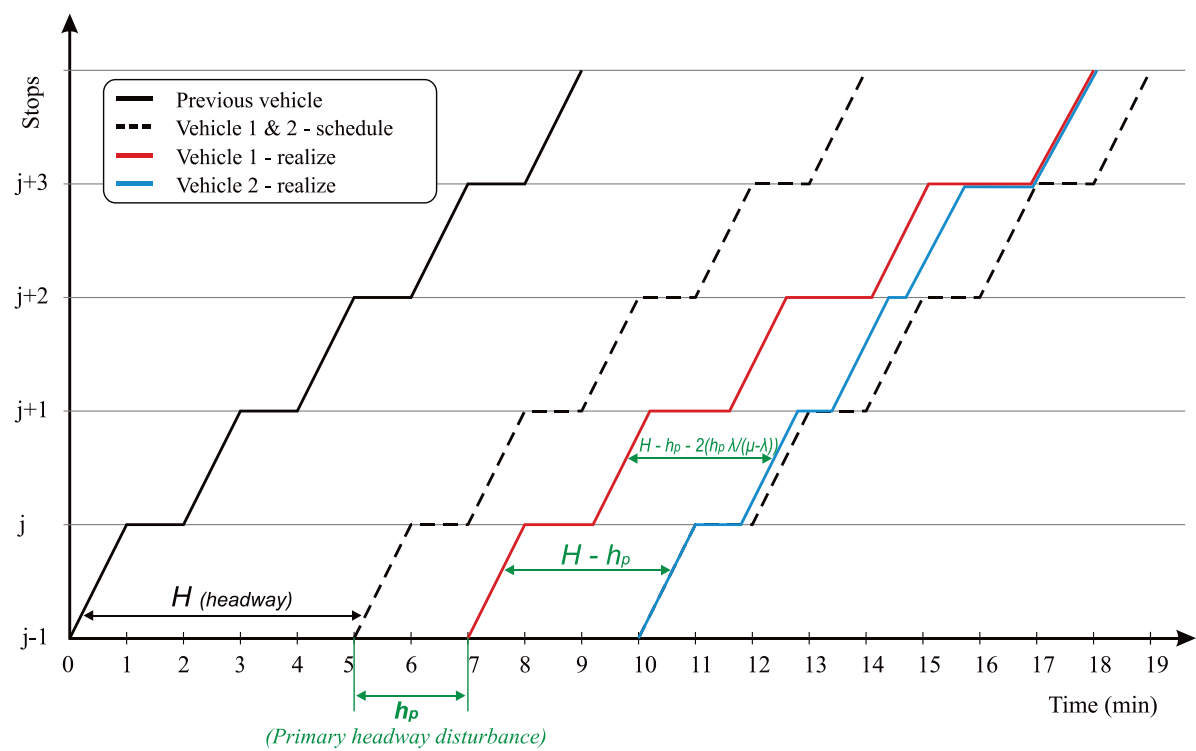

Figure 2 Spatial-temporal diagram of headway disturbance propagation to subsequent departure

Headway disturbance propagation for Vehicle 2 is defined by the size and location of the realized disturbance, mean passenger accumulation intensity, and mean passenger boarding intensity. When the size of headway disturbance for Vehicle 2 at each stop along the line $\left(h_{2, s}\right)$ is expressed through the primary disturbance (Eq. (10)), and the function describing Vehicle 1 travel pattern (Eq. (9)), mathematical order is produced. Reduction of this mathematical order yields an equation describing the headway disturbance propagation by stops for Vehicle 2, i.e., Eq. (11).

$h_{2, s}=-h_{\mathrm{p}}(s-1) \frac{\lambda}{\mu}\left(1+\frac{\lambda}{\mu}\right)^{s-2}$

Using the location of the primary headway disturbance as a reference point, analogously to the above, an equation describing the headway disturbance propagation by stops for Vehicle 3 is derived, i.e., Eq. (12). $h_{3, s}=h_{\mathrm{p}} \frac{(s-1)(s-2)}{2}\left(\frac{\lambda}{\mu}\right)^{2}\left(1+\frac{\lambda}{\mu}\right)^{s-3}$

Using Eq. (9), Eq. (10), Eq. (11) and Eq. (12), general headway disturbance propagation model is obtained pertaining to subsequent scheduled departures, i.e., Eq. (13)

$h_{k, s}=h_{\mathrm{p}} \frac{(s-1) !}{(k-1) !(s-k) !}\left(-\frac{\lambda}{\mu}\right)^{k-1}\left(1+\frac{\lambda}{\mu}\right)^{s-k}$

where: $h_{k, s}$ - headway disturbance for vehicle $k$ at the stop $s$ (min); $s$-number of stops along the line from the one at which the primary headway disturbance occurred; $k$ - vehicle schedule number relative to the one that has caused the primary headway disturbance; $\lambda$ - mean passenger accumulation intensity (passenger $/ \mathrm{min}$ ); $\mu$ - mean passenger boarding intensity (passenger $/ \mathrm{min}$ ); $h_{\mathrm{p}}$ - primary headway disturbance.

In line with extant studies $[4,15]$, parameter $\beta$ is incorporated into the model, describing the relationship 
between passenger accumulation intensity and passenger boarding intensity. Parameter $\beta$ is defined by Eq. (14).

$\beta=\frac{\lambda}{\mu}$

Hence, Eq. (13) can be expressed as a function $h_{(h p, s, k, \beta)}$ Eq. (15).

$$
h_{\left(h_{\mathrm{p}}, k, s, \beta\right)}=h_{\mathrm{p}} \frac{(s-1) !}{(k-1) !(s-k) !}(-\beta)^{k-1}(1+\beta)^{s-k}
$$

\section{Parameter effect analysis}

Using Eq. (15), effects of individual parameters on the headway disturbance propagation are analyzed. In the transport system, headway disturbance propagation is determined by: primary headway disturbance size $\left(h_{\mathrm{p}}\right)$, parameter $\beta$, number of stops along the line from the one at which the primary headway disturbance occurred $(s)$, and vehicle schedule number $(k)$. Primary headway disturbance size directly affects the headway disturbance size of all vehicles along the line. However, as its influence is linear, it is omitted in the subsequent analyses. In the analyses that follow, the primary headway disturbance size is thus assumed constant and is assigned the value of 1 minute.

Headway disturbance propagation, as a function $h_{(s, k, \beta)}$, can be both positive and negative, and is defined in the set of real numbers. Number of stops along the line from the one at which the primary headway disturbance occurred and vehicle schedule number are defined in the set of natural numbers. Parameter $\beta$, in line with Eq. (14), is defined in the semi-open interval $(0,1]$.

In order to determine the effect of individual parameters on the headway disturbance propagation, Fig. 3, Fig. 4 and Fig. 5 were created, depicting headway disturbance propagation as a function of number of stops for various combinations of $\beta$ and $k$ values.

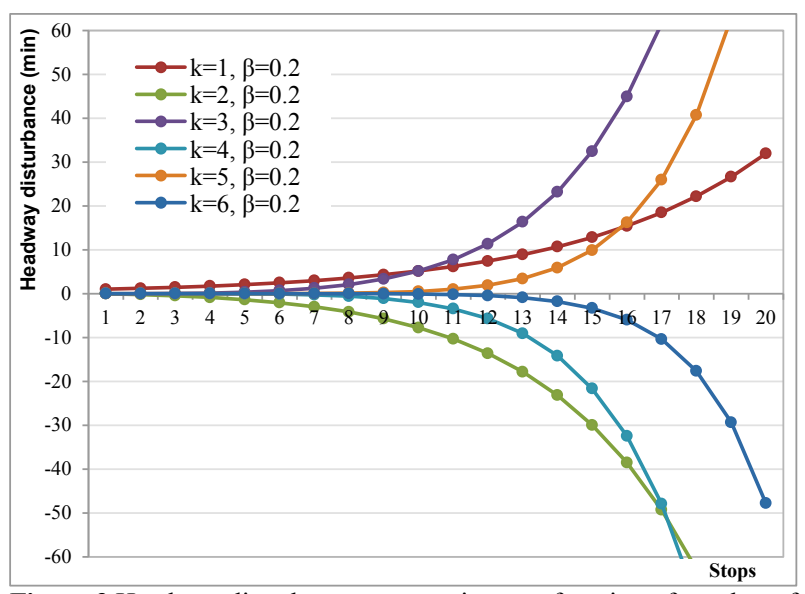

Figure 3 Headway disturbance propagation as a function of number of stops for different departures $\left(h_{\mathrm{p}}=1 \mathrm{~min}, \beta=0,2\right)$

It can be seen from Fig. 3 that the headway disturbance propagation function $h_{(s, k, \beta)}$ in the domain defining the Vehicle 1,3 and 5 departures is monotonically increasing, whereas that pertaining to
Vehicle 2, 4 and 6 departures is monotonically decreasing.

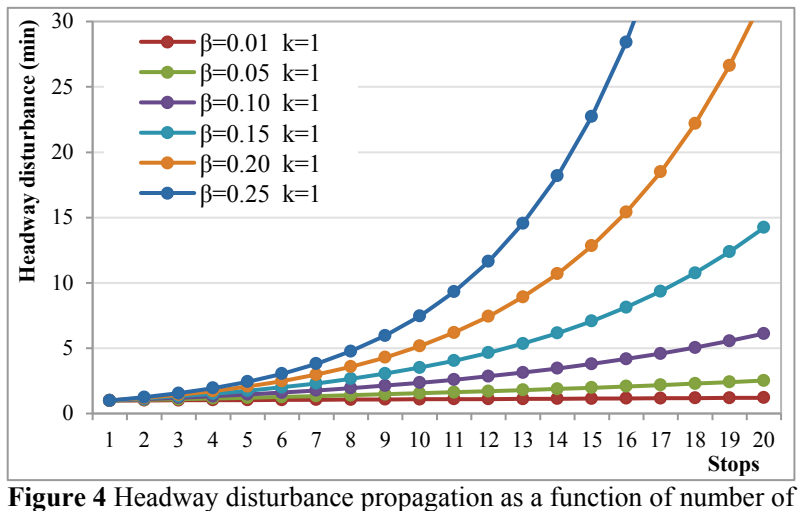

Figure 4 Headway disturbance propagation as a function of numb
stops for different parameter $\beta$ values $\left(h_{\mathrm{p}}=1 \mathrm{~min}, k=1\right)$

Fig. 3, Fig. 4 and Fig. 5 reveal that changes in the function $h_{(s, k, \beta)}$ increment across stops are dependent on parameters $\beta$ and $k$. More specifically, an increase in parameter $\beta$ results in a greater function increment, whereas parameter $k$, in addition to its other effects, also changes the sign of the function.

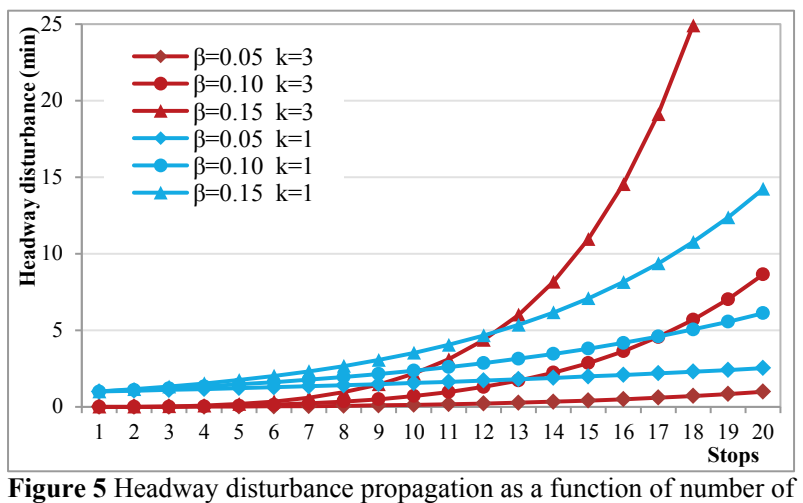
stops for different parameter $\beta$ values for Vehicle 1 and 3 ( $h=1 \mathrm{~min})$

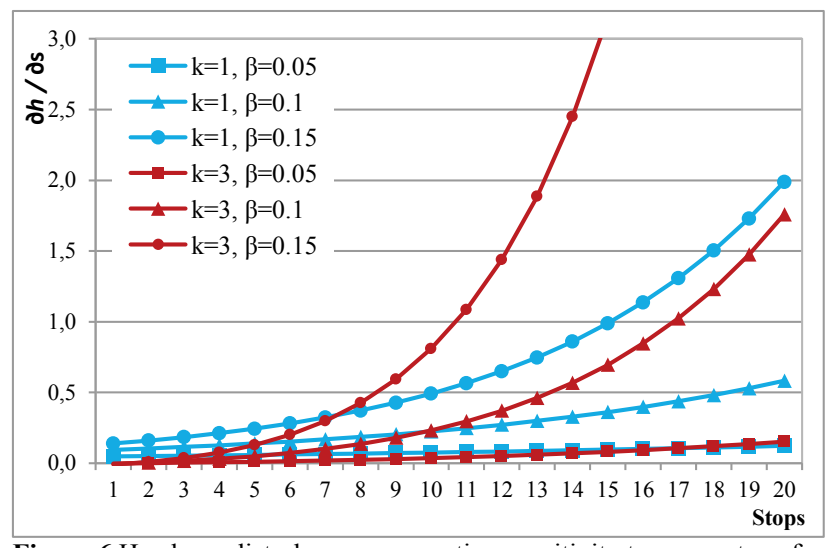

Figure 6 Headway disturbance propagation sensitivity to parameter $s$ for different parameter $\beta$ values for Vehicle 1 and $3\left(h_{\mathrm{p}}=1 \mathrm{~min}\right)$

When the primary headway disturbance occurs, function $h_{(s, k, \beta)}$ increment is of particular relevance for the system state. In the case of pronounced increment, the system transitions into an uncontrolled state, are accompanied by vehicle clustering along the line. In line with the above, it is possible to analyze headway disturbance propagation sensitivity to parameters $s$ and $\beta$. 
Headway disturbance propagation sensitivity is described by partial derivatives $\frac{\partial h}{\partial s}$ and $\frac{\partial h}{\partial \beta}$.

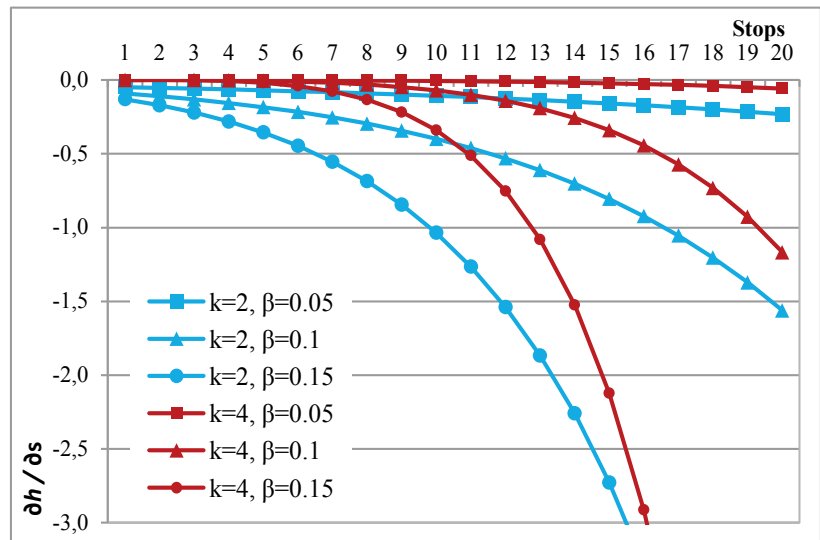

Figure 7 Headway disturbance propagation sensitivity to parameter $s$ for different parameter $\beta$ values for Vehicle 2 and $4\left(h_{\mathrm{p}}=1 \mathrm{~min}\right)$

Fig. 6 and Fig. 7 demonstrate that, for odd departure schedules, extending the distance between the vehicle and the primary headway disturbance source results in a continuous increase in the headway disturbance propagation sensitivity to parameter $s$ (i.e., increment is positive), whereas its effect decreases (i.e., increment is negative) for vehicles with even departure schedules. In addition, the headway disturbance propagation sensitivity to parameter $s$ becomes greater with the increase in $\beta$.

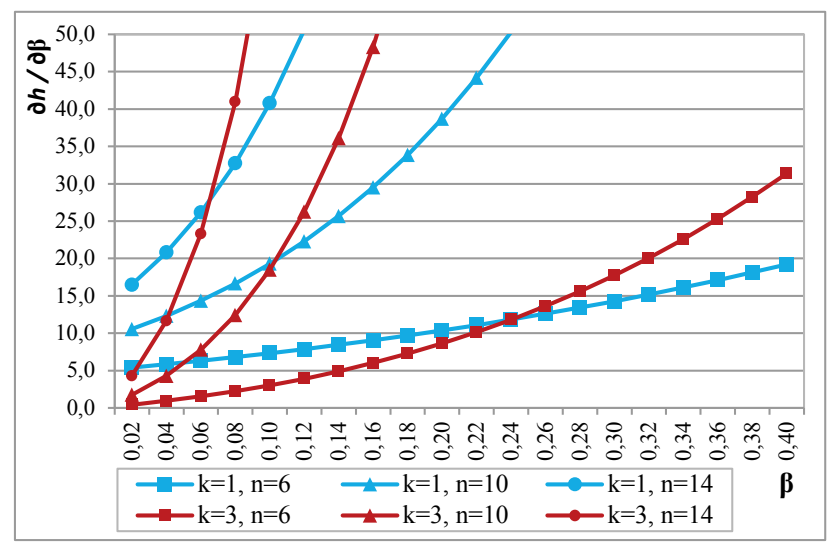

Figure 8 Headway disturbance propagation sensitivity to parameter $\beta$ for different parameter $s$ values for Vehicle 1 and $3\left(h_{\mathrm{p}}=1 \mathrm{~min}\right)$

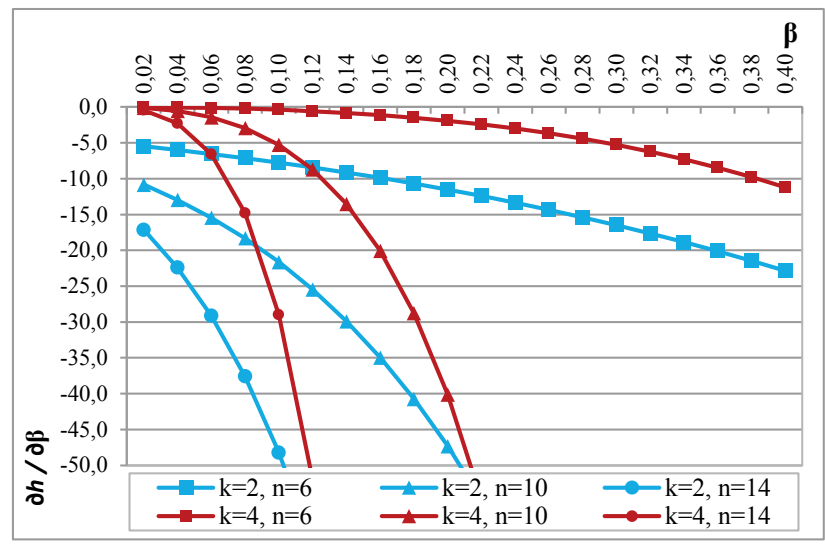

Figure 9 Headway disturbance propagation sensitivity to parameter $\beta$ for different parameter $s$ values for Vehicle 2 and $4\left(h_{\mathrm{p}}=1 \mathrm{~min}\right)$
Based on Fig. 8 and Fig. 9, the headway disturbance propagation sensitivity to parameter $\beta$ is derived analogously to the approach used for determining sensitivity to $s$. Comparative analysis of partial derivatives $\frac{\partial h}{\partial s}$ and $\frac{\partial h}{\partial \beta}$ leads to the conclusion that the headway disturbance propagation is more sensitive to the changes in parameter $\beta$, relative to the effects of changes in parameter $s$.

Generally, it can be concluded that function $h_{(s, k, \beta)}$ increment depends on the parameter $s, k$ and $\beta$ values.

It can be seen in Fig. 6, Fig. 7, Fig. 8 and Fig. 9 that a specific critical increment in the function $h_{(s, k, \beta)}$ induces uncontrolled system state. For the assumed critical increment value, joint parameter $s, k$ and $\beta$ influence curves were created (Fig. 10, Fig. 11, Fig. 12 and Fig. 13). The critical increment value pertains to the function increment of 45 and -45 degrees, for odd and even numbered vehicle departures, respectively.

Fig. 10 depicts the difference in the laws governing curve $k=1$ propagation relative to others, which arises due to Vehicle 1 headway disturbance propagation not being affected by any preceding vehicles.

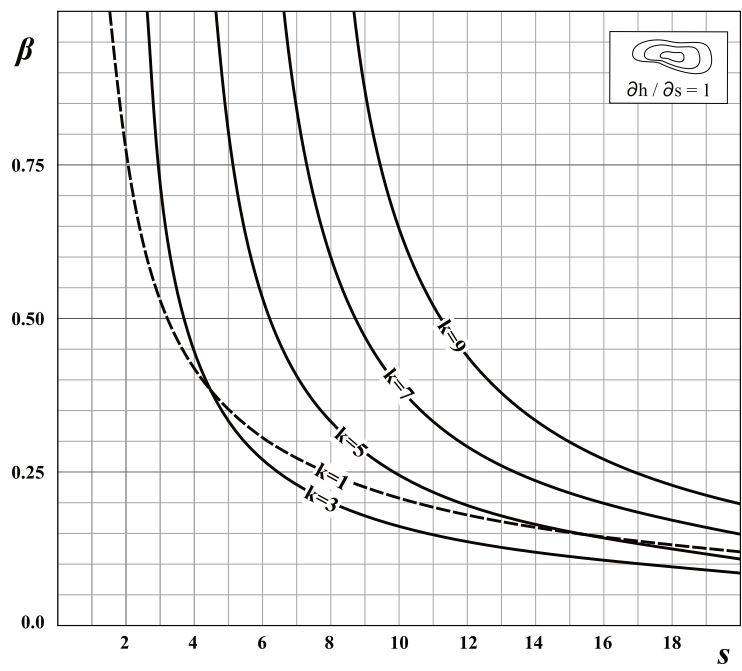

Figure 10 Graphical representation of $\partial h / \partial s$ curves for function increment by 45 degrees

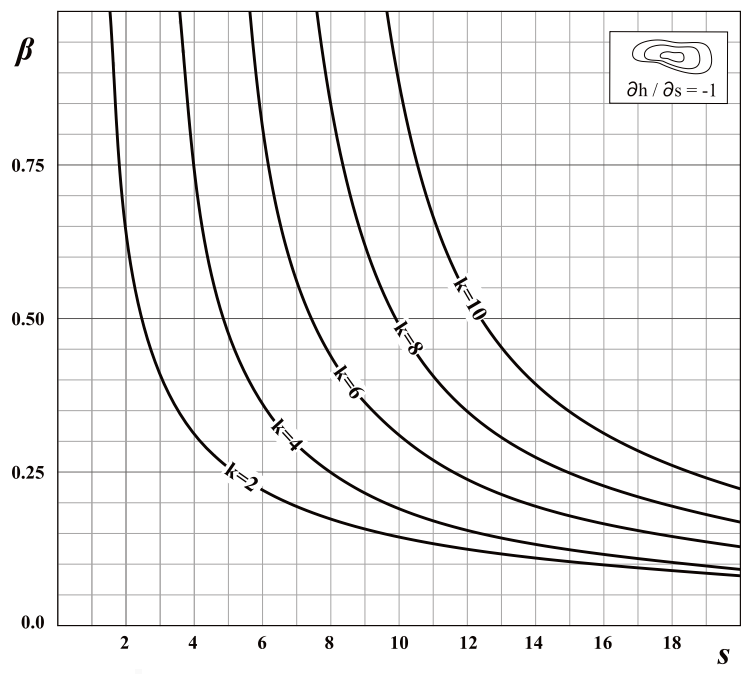

Figure 11 Graphical representation of $\partial h / \partial s$ curves for function increment by -45 degrees 


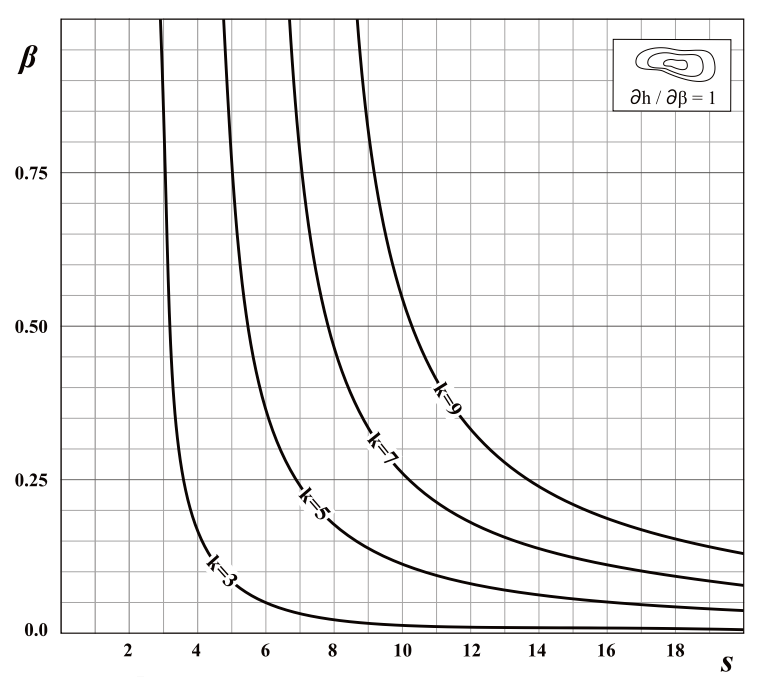

Figure 12 Graphical representation of $\partial h / \partial \beta$ curves for function increment by 45 degrees

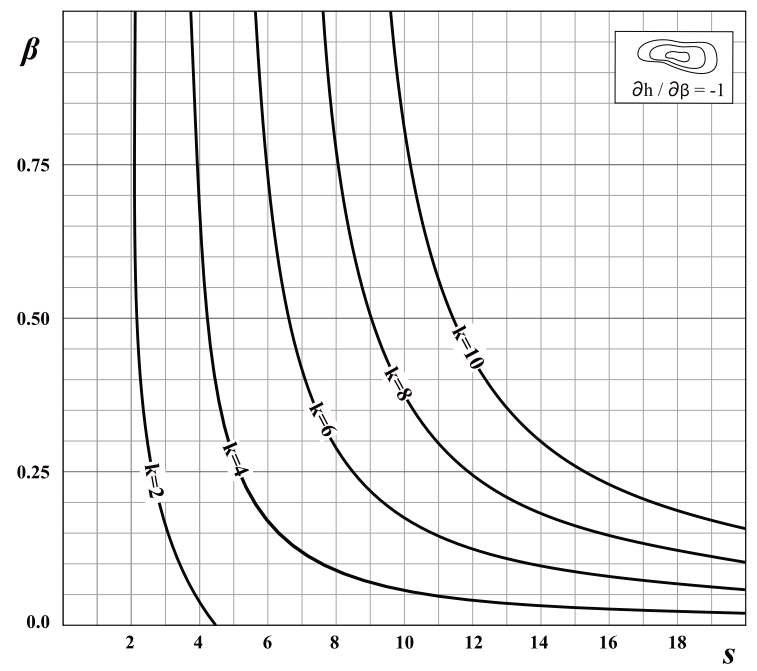

Figure 13 Graphical representation of $\partial h / \partial \beta$ curves for function increment by -45 degrees

Curves presented in Fig. 10, Fig. 11, Fig. 12 and Fig. 13 concur with the earlier statement that the headway disturbance propagation is more sensitive to the changes in parameter $\beta$ than it is to the changes in parameter $s$. For a particular $\beta$ value and a predefined number of stops along the line $s$, headway disturbance propagation attenuates when transferred to the consecutive vehicle. Hence, unless critical function $h_{(s, k, \beta)}$ increment is reached, the system state tends to stabilize.

\section{Conclusion}

The paper presented analysis of headway disturbance propagation by stops along the line, as well as scheduled vehicles. In the extant literature, several authors addressed the headway disturbance issue, predominantly by examining the headway disturbance effects on passengers or by creating strategies for operational headway management. To date, very few studies focused on evaluating effects of individual parameters on the headway disturbance.

By analyzing vehicle travel process, in this work, it was possible to derive modeling parameters. Headway disturbance propagation was defined via parameters determining vehicle dwell time at stops. Parameters that were incorporated into the model comprised of primary headway disturbance size, passenger accumulation intensity, passenger boarding intensity, number of stops between the source of the primary disturbance and current vehicle position, and vehicle schedule number relative to that of the vehicle that generated the primary disturbance. The developed deterministic model was employed in the analysis and ranking of parameter influence on headway disturbance propagation.

Headway disturbance propagation stems from the complex interaction of a number of parameters. Thus, assessing the influence of only one parameter does not provide a comprehensive perspective on headway disturbance propagation. In the model, number of stops between the source of the primary disturbance and the current vehicle position and parameter $\beta$ emerged as predominant parameters.

Increase in the passenger accumulation intensity to boarding ratio results in greater system sensitivity to headway disturbance propagation [15]. In urban public transport, line length and number of stops proportionally contribute to headway discrepancies $[11,12,16,17]$.

Based on the analyses conducted here, it can be concluded that headway disturbance propagation in the system is more sensitive to the changes in parameter $\beta$, relative to the number of stops along the line.

The realized headway disturbance cumulatively increases with each consecutive stop along the line. Consequently, greater number of stops increases the risk of cumulative disturbance that may result in uncontrolled system state.

Parameters defined by the model and the findings yielded by the analyses confirm that it is possible to mitigate headway disturbance issues during the transport system design phase.

By optimizing the parameters identified in this work during the system design phase, its robustness to primary headway disturbance propagation increases. For example, while designing the public transport network, radial lines could be assigned preference relative to diametrically oriented ones, as this has a positive effect on headway. Increasing the passenger exchange intensity affects parameter $\beta$, and can be achieved through, for example, modifying the exchange regimen, introduction of vehicles with reduced floor height, and changes in fare payment and verification, among other measures. For attaining the most optimal results with respect to headway uniformity along specific urban public transport lines, in addition to operational measures, parameters that affect headway emergence and propagation can be mitigated in the transport system design phase.

\section{References}

[1] Liu, R.; Sinha, S. Modelling Urban Bus Service and Passenger Reliability. // Proceedings of Instr 2007 conference, The Hague, 2007.

[2] Simeunovic, M.; Lekovic, M.; Papic, Z., Pitka, P. Influence of vehicle headway irregularity in public transport on invehicle passenger comfort. // Scientific Research and Essays. 7, 32(2012), pp. 2874-2881.

https://doi.org/10.5897/SRE12.091 
[3] Ceder, A. Public Transit Planning and Operation: Theory, modelling and practice, Technion-Israel Institute of Technology, Haifa, 2007.

[4] Daganzo, C. F. A headway-based approach to eliminate bus bunching: Systematic analysis and comparisons. // Transportation Research Part B: Methodological. 43, 10(2009), pp. 913-921. https://doi.org/10.1016/j.trb.2009.04.002

[5] Daganzo, C. F.; Pilachowski, J. Reducing bunching with bus-to-bus cooperation. // Transportation Research Part B: Methodological, 45, 1(2011), pp. 267-277. https://doi.org/10.1016/j.trb.2010.06.005

[6] Xuan, Y.; Argote, J.; Daganzo, C. F. Dynamic bus holding strategies for schedule reliability: Optimal linear control and performance analysis. // Transportation Research Part B. $45,(2011)$, pp. 1831-1845. https://doi.org/10.1016/j.trb.2011.07.009

[7] Bartholdi, J. J. (III); Eisenstein, D. D. A self-coordinating bus route to resist bus bunching. // Transportation Research Part B. 46, 4(2012), pp. 481-491. https://doi.org/10.1016/j.trb.2011.11.001

[8] Hickman, M. D. An analytic stochastic model for the transit vehicle holding problem. // Transportation Science. 35, 3(2001), pp. 215-237. https://doi.org/10.1287/trsc.35.3.215.10150

[9] Bellei, G.; Gkoumas, K. Transit vehicles' headway distribution and service irregularity. // Public Transport. 2010, pp 269-289.

[10] Oort, V. N. Incorporating service reliability in public transport design and performance requirements: International survey results and recommendations. // Research in Transportation Economics. 48, (2014), pp. 92100. https://doi.org/10.1016/.retrec.2014.09.036

[11] Xumei, C.; Lei, Y.; Yushi, Z.; Jifu, G. Analyzing urban bus service reliability at the stop, route, and network levels. // Transportation Research Part A, 17A, 2(2009), pp. 107113.

[12] Pitka, P.; Simeunović, M.; Saulić, H. Uniformity headway analysis of urban public transport. // Suvremeni promet. 35, 1-2(2015), pp.136-140.

[13] Delgado, F.; Munoz, J.; Giesen, R.; Cipriano, A. Real-Time Control of Buses in a Transit Corridor Based on Vehicle Holding and Boarding Limits. // Transportation Research Record. 2090, (2009), pp. 59-67. https://doi.org/10.3141/2090-07

[14] Newell, G. F.; Potts, R. B. Maintaining a bus schedule. // Proceedings of $2^{\text {nd }}$ Australian Road Research Board. 2(1964), pp. 388-393.

[15] Vuchic, V. R. Propagation of schedule disturbances in linehaul passenger transportation. // UITP Revue. 18, 4(1969), pp. 281-285.

[16] Schedule instability and control. // Fundamentals of Transportation and Traffic Operations / Daganzo F. Carlos. Nrw York: Elsevier, 1997. pp. 304-309.

[17] Oort, V. N. Service Reliability and Urban Public Transport Design, PhD thesis, Netherlands, 2011.

[18] Simeunović, M. Quality of transport services in transit as a consequence of the interdependence of static and dynamic parameters, Master's thesis, Novi Sad, 2001.

[19] Vuchic, V. Urban Transport Operation, Planning and Economics. John Viley \& Sons Inc., Hoboken, New Jersey, 2005.

\section{Authors' addresses}

Pavle Pitka, PhD Candidate

University of Novi Sad

Faculty of Technical Sciences Department of Traffic Engineering

Trg Dositeja Obradovića 6

21101 Novi Sad, Serbia

pitka@uns.ac.rs

Milan Simeunović, Prof. Dr

University of Novi Sad

Faculty of Technical Sciences

Department of Traffic Engineering

Trg Dositeja Obradovića 6

21101 Novi Sad, Serbia

milansim@uns.ac.rs

Ilija Tanackov, Prof. Dr

University of Novi Sad

Faculty of Technical Sciences

Department of Traffic Engineering

Trg Dositeja Obradovića 6

21101 Novi Sad, Serbia

ilijat@uns.ac.rs

Tatjana Savković, PhD Candidate

University of Novi Sad

Faculty of Technical Sciences

Department of Traffic Engineering

Trg Dositeja Obradovića 6

21101 Novi Sad, Serbia

savkovic.t@uns.ac.rs 